\title{
Project NANO (nanoscience and nanotechnology outreach): a STEM training program that brings SEM's and stereoscopes into high-school and middle-school classrooms
}

Sherry Cady, Mikel Blok, Keith Grosse, Jennifer Wells

Sherry L. Cady, Mikel Blok, Keith Grosse, Jennifer Wells, "Project NANO (nanoscience and nanotechnology outreach): a STEM training program that brings SEM's and stereoscopes into high-school and middle-school classrooms," Proc. SPIE 9236, Scanning Microscopies 2014, 92360Q (16 September 2014); doi: 10.1117/12.2084632

SPIE Event: SPIE Scanning Microscopies, 2014, Monterey, California, United States 


\title{
Project NANO (nanoscience and nanotechnology outreach): a STEM training program that brings SEM's and stereoscopes into high- school and middle-school classrooms
}

\author{
Sherry L. Cady Pacific Northwest National Lab. (United States) \\ Mikel Blok Beaverton High School (United States) \\ Keith Grosse Lake Oswego High School (United States) \\ Jennifer Wells Portland State University (United States)
}

\begin{abstract}
The program Project NANO (Nanoscience and Nanotechnology Outreach) enables middle and high school students to discover and research submicroscopic phenomena in a new and exciting way with the use of optical and scanning electron microscopes in the familiar surroundings of their middle or high school classrooms. Project NANO provides secondary level professional development workshops, support for classroom instruction and teacher curriculum development, and the means to deliver Project NANO toolkits (SEM, stereoscope, computer, supplies) to classrooms with Project NANO trained teachers. Evaluation surveys document the impact of the program on student's attitudes toward science and technology and on the learning outcomes for secondary level teachers. Project NANO workshops (offered for professional development credit) enable teachers to gain familiarity using and teaching with the SEM. Teachers also learn to integrate new content knowledge and skills into topic-driven, standards-based units of instruction specifically designed to support the development of students' higher order thinking skills that include problem solving and evidence-based thinking. The Project NANO management team includes a former university science faculty, two high school science teachers, and an educational researcher. To date, over 7500 students have experienced the impact of the Project NANO program, which provides an exciting and effective model for engaging students in the discovery of nanoscale phenomena and concepts in a fun and engaging way.
\end{abstract}

KEYWORD LIST: SEM, optical microscope, stereoscope, electron beam technology, education, middle school, high school, secondary education, professional development, STEM.

\section{OVERVIEW OF THE PROGRAM}

To increase science achievement for all students, Project NANO was designed to enable middle and high school students to discover and research submicroscopic phenomena in a new and exciting way with the use of optical and scanning electron microscopes in the familiar surroundings of their middle or high school classrooms. The program centers on offering secondary teacher training workshops that equip the teachers with the skills required to use an SEM and stereoscope, teach with the tools, build lesson plans that utilize the tools, and improve their classroom delivery and effectiveness at teaching with the tools. The program also delivers the Project NANO toolkits throughout the academic year to those school classrooms taught by Project NANO trained teachers. The toolkits include a table-top SEM, stereoscope, computer, and various types of sample preparation supplies and standard samples for calibration and SEM performance evaluation. Students experience the SEM in classes and in after-school sessions for those teachers that encourage their students to use the SEMs for science projects and open exploration of samples using the microscopes. The Project NANO toolkits are also booked and used in schools for student research over winter and spring breaks.

Students that participate in Project NANO are disbursed in middle and high schools in the Beaverton, Hillsboro, Forest Grove, Gresham-Barlow and North Clackamas school districts, West Linn-Wilsonville, and Lake Oswego School Districts and Portland Public Schools, and two independent schools in the Portland area. Though the program has reached capacity in terms of the number of new schools that can be served with the existing two toolkits for any one academic year, we are now training multiple teachers in the same schools so that the tools get used more often and less deliveries are required. This strategy enables teachers at the same school to co-plan units of instruction that logically

Scanning Microscopies 2014, edited by Michael T. Postek, Dale E. Newbury, S. Frank Platek, Tim K. Maugel, Proc. of SPIE Vol. 9236, 92360Q - (c) 2014 SPIE · CCC code: 0277-786X/14/\$18 - doi: 10.1117/12.2084632 
scaffold nanoscale science and technology experiences up through the grades and presents new opportunities to support teacher's efforts to work in a cross-disciplinary manner by co-planning units with mathematics and statistics, art, and language arts teachers.

Project NANO is a partnership between the teachers who enroll in the workshop, a professional development course taught at a local university, and the Project NANO management team, which consists of a university faculty, two high school science teachers, and an educational researcher. A combination of workshop training, in-class support, teacher-Project NANO staff follow-up and assessment provide the participating teachers with the support they need to develop the skills and content knowledge required to teach their students how to engage in inquiry-based science projects using the microscopes. The assessment piece provides a means to evaluate learning outcomes for students and the secondary level teachers that participate and partner with Project NANO.

Project NANO assessments have been instrumental in enabling us to evaluate how teacher participants in Project NANO negotiate the inclusion of nanoscience content and microscopy into the science curriculum and determine the various ways in which the teachers demonstrate content knowledge gains and pedagogical content knowledge gains in response to the Project NANO teacher-training workshops. The data collection procedures involve measuring student learning outcomes and describing teacher thinking as they negotiate the integration of nanoscale science content and technology into the curriculum.

Student learning outcomes metrics include standardized student on-line, pre- and post-content tests and student work sample scores. The study tracks the number of students involved in classes that include a Project NANO unit that draws upon the use of the SEM and stereoscope to conduct scientific research for an assignment. The study also tracks the number of students formally involved in a Project NANO unit who go on to major in science, technology, engineering or mathematics in college over the next three years. These data are gathered using an on-line survey sent to teachers and graduates each year.

Teachers' thinking is explored and described using five approaches; (1) pre- and post-content tests developed and implemented by the Project NANO workshop co-instructors, (2) teachers' Content Representations (CoRe) analysis developed with teachers during the summer workshops pre-unit planning exercise (which consist of teachers' units of instruction plan scores (i.e., a blank sample CoRe table is attached), (3) "call-outs" or short-written or audio-recorded reflections based on CoRe as they develop and teach lesson plans, (4) focus group interviews and individual interviews (as requested as an alternative to focus groups) with participating teachers, and (5) classroom observations in a subsample of participants' classes conducted using The Educators Evaluating the Quality of Instructional Products. The educational research is facilitated via a Human Subjects Review Board granted permit, which facilitates the researcher drawing upon the teachers writing on the CoRe and their call-out reflections to guide the development of the focus group interview questions.

\section{SECONDARY LEVEL PROFESSION DEVELOPMENT WORKSHOPS}

The Project NANO workshops are designed so that the teachers can learn how to enable their students to use an SEM with directed and inquiry-based science lesson plans that they develop as part of their training in the program.

Teacher professional development workshops are held in the summers at local high school science classrooms. The teachers receive credit for taking either an introductory or an advanced course through a local university. The advanced workshops extend and enhance the skills of the teachers and enable them to test more types of samples on the microscope, receive assistance in problem-solving technical and pedagogical issues, revise/share the instructional unit they developed in the introductory workshop and/or develop a new unit of instruction that fits within new classes they teach the following academic year. It is non uncommon for teachers in public schools to be asked either to teach a different class or two in subsequent years. Other teachers often teach a variety of classes on a biennial or triennial rotational teaching schedule. Hence our strategy to provide both an introductory and advanced Project NANO workshop retains teachers in the program and keeps them engaged in developing/refining course lesson plans that engage students in nanoscale science in a variety of different secondary classes. 
Themes of the lesson plans and instructional units developed in the Project NANO professional development workshops have included forensic science, biological adaptations, acid and base chemistry, chemical mixtures and pure substances, engineering design and processes related to material properties, and units that emphasized explorations of the concepts of size and scale. As the units of instruction generated by earlier program participants are refined and modified with continued use, the teachers find that they can contribute additional information that helps the next cohort of teachers to develop higher quality units of instruction.

The Project NANO teachers in the advanced workshops have reported in interview and call-out reflections that they have improved their own understanding of student thinking in response to instructional strategies and the content covered in the unit. In addition, student performance has improved in response to improvements made to the revised lessons. In addition to the professional development training the Project NANO teachers receive via the workshops, the management team supports teachers efforts to integrate new content knowledge and skills used to develop topic-driven, standards-based units of instruction specifically designed to support the development of students' higher order thinking skills such as problem solving and evidence-based thinking. The additional support provided to teachers has helped inform the program and improve the teacher training workshops.

\section{LEANING FORWARD TEACHER PROFESSIONAL DEVELOPMENT STANDARDS}

A key challenge for a nanoscale science professional develop workshop is that most secondary science teachers are specialists trained in one or two disciplines of science. However investigating matter at the nanoscale and conducting scientific inquiries involving the use of electron microscopy is by its very nature, an interdisciplinary experience. Furthermore, most chemistry and physics teachers and many middle level teachers do not involve microscopy in their teaching practices, therefore many of those involved in Project NANO have not worked with any type of microscope in a teaching and learning context since they were in college themselves. Although many life science and some middle level teachers do involve basic dissecting microscopes and hand lenses in some of the units of instruction they teach, every participants in Project NANO is new to the experience of facilitating secondary level learning using a scanning electron microscope.

Given this context, Project NANO approaches professional development from the perspective that all of the participants in the program require more support than a brief introduction as to how the instruments work and what the various button do. Indeed, countless examples exist of marginally successful and unsuccessful programs that have done this, as is evidenced by the huge number of dusty, unopened packages of digital scientific instruments stored in teachers' supply closets through the nation.

Instead of repeating mistakes from the past, we ascribe to the National Staff Development Council ${ }^{1}$ Learning Forward teacher professional development (PD) standards that state that professional development should be sustained and intensive. According to these standards, in the case of STEM education, professional development should be presented within the context of authentic science inquiry experiences and involve the authentic work of teaching and learning by supporting the development, implementation and refinement of units of instruction over time. ${ }^{1}$

Thus, Project NANO involves initial immersive experiences in the summer where teachers play the role of learners working in groups to conduct scientific inquiries taking frequent opportunities to pause to discuss the implications of the content and technology on teaching and learning within various contexts. They immediately apply their knowledge as adaptive experts ${ }^{2,3}$ as they develop two-to-three week units of instruction and then receive on-going support from a network of experts during the academic year to assist with technical challenges and ensure a deeply reflective experience that informs improvements to the units.

\section{NETWORK IMPROVED COMMUNITY APPROACH}

Project NANO works to leverage resources across traditional institutional boundaries to support teachers and students involved in the program. Drawing on Bryk and Gomez's model ${ }^{4}$ of Network Improvement Communities, our team consists of people who bring a variety of resources and expertise to the program. As noted, our management team 
is comprised of a disciplinary faculty scientist who specializes in geology and microbiology, two veteran high school teachers that serve as teachers on special assignment (TOSAs), industry partners and a university-based science education researcher.

The involvement of our veteran science teachers on special assignment (TOSAs) is key to ensuring a high level of credibility in the minds of teacher participants. Participants have expressed that they trust the applicability of what they learn through Project NANO in their own classes because they view their coaches as teachers who are fully aware of many of the challenges teachers and students face. The educational researcher provides internal evaluation support and conducts design-based research on the program with the intention of informing improvements to the professional development, the nanoscale units of instruction developed by participants, and by extension, improvements to science education and engineering design teaching practices overall. The goal of assembling our diverse team is to create cultural bridges between school and university level science education and industry. By doing so, we gain access to leading edge tools of science including technical and theoretical perspectives as well as ensure that programming is consistent with modern educational reform practices that are consistent with those found in the participating schools.

Another key feature of the program is that it is tremendously impactful that every teacher involved in the program knows that they are all new to teaching nanoscale science using an SEM. Thus, there is reduced resistance among the teachers to revealing what they do not know based on the awareness that no one will think of them as being unprofessional when they reveal gaps in knowledge. Consequently, there is an openness to sharing ideas and receiving suggestions that often times does not exist when teachers are discussing common problems of practice. This aspect of the program is pivotal to the success of what we are doing because we do not intend for participants to develop and teach a nanoscale unit of instruction once or twice on a project basis and fail to refine their unit or worse, then consider themselves done with nanoscale science. Instead, we have intentionally created a network of support for teachers to test and refine the structure of their nanoscale science or engineering units, adapt instructional strategies to meet the needs of diverse classes of students and develop theories of practice that deeply inform their rationale for how to respond to content and student thinking over time.

At the center of the Networked Improvement Community are the teachers and their students involved in the program. Again, Project NANO is currently operational in eight school districts and two independent schools the region. The schools and classes involved in Project NANO represent a very broad demographic of participants. For example, many of the schools involved are high needs schools with greater than $50 \%$ of the students on free and reduced lunch and a high proportion of English language learners at an early level of English language acquisition. Some of these same schools are Talented and Gifted programs for students who fall within the top 98 percentile of intelligence while others have a high percentage of students with a variety of special needs including learning disabilities and others rank among the highest socio-economic schools in the region.

Because the students involved in Project NANO come to the project with highly diverse background knowledge and experiences, it is key to the success of the program that the teachers themselves bring their knowledge of content, curriculum, instructional strategies, assessment and student thinking or, their pedagogical content knowledge $\mathrm{e}^{5}$, to the process of negotiating the inclusion of nanoscale content and technology into the curriculum. Next, we will describe our approach to supporting this process beginning with a description of the summer workshop.

\section{EVALUATION SURVEYS}

Project NANO evaluation surveys were designed to document the impact of the program on student attitudes toward science and technology and on the learning outcomes for secondary teachers.

Student Learning Outcomes. Students participate in an on-line pre- and post-Project NANO lesson plan survey, which asks them to self-evaluate their own experience and level of proficiency related to the use of microscopes and their interest in using the SEM to conduct research or as part of a possible career option. As one might expect given the expectation that teachers will train their students to use the tools effectively, students consistently demonstrate an increase in their scores between the pre- and post-surveys. An unexpected impact of the program was the impressive scores that the students involved in the nanoscale science units of instruction earned on their units of instruction. Each 
year, an increasing number of the participating teachers submit their student's unit scores. It is notable that second year teachers in the program report in interview and call-out reflections that as they have improved their own understanding of student thinking in response to instructional strategies and the content covered in the unit. In addition, student performance is improving in response to improvements made to the revised lessons.

Teacher Learning Outcomes. Overall, teachers demonstrate a high level of ability to conceptualize how to fit nanoscale science and technology into their curriculum using open-ended or guided science inquiry teaching strategies. Teachers also demonstrate gains related to the integration of nanoscale topics to improve student's understanding of scientific concepts and processes taught at the secondary level. It is worth noting that teachers supported by their coaches and colleagues in the program are able to strengthen their units and report that that would not have taught their nanoscale unit without the support of their Project NANO coaches, colleagues, and the materials made available through the summer workshop and program website. Regardless of their entry points, we have found that teachers gain sufficient skills to demonstrate how to properly use the SEM and the stereoscopes in a Project NANO toolkit, and how to use the skills they gained as workshop participants to facilitate others using the technologies to examine specific characteristics of specimens. They also gain the ability to capture high-quality images on both types of microscopes, save and transfer images, and master sample preparation, skills they transfer as part of their lesson plans to their students. Nearly every lesson plan / instructional unit developed in the teacher training workshops asks students to draw upon prior knowledge and make new connections, to work in lab groups, and they provide opportunities for students to use critical thinking skills to make and share observations and problem solve together. Each lesson plan requires that the students communicate their observations and, in some cases, defend their findings.

Project NANO teachers have consistently demonstrated statistically significant content gains on their pre- and post-surveys and demonstrate high levels of proficiency in using the SEM themselves and in terms of facilitating students in performance-based exams. First year teachers in the program reported in call-outs, interviews and classroom observations that their students performed well in the nanoscale unit in comparison to the past units they taught that involved novel concepts and technologies. Teachers attributed the lack of a significant implement dip in terms of student outcomes to the fact that they learned a great deal from the summer workshop, colleagues involved in the program, sample unit elements found on the program website and from their coaches. In fact, all but one of the incoming cohort members specifically stated that they would not have taken the risk to teach a nanoscale unit and potentially waste valuable instructional time were it not for the supports provided by Project NANO.

Teachers reported in their call-outs and in response to a brief survey that while they are still in the process of developing their own competencies for understanding nanoscale concepts and technology, they are focused more on providing students with non-competitive opportunities to present their science research findings rather than on science competitions. All but one teacher involved their students in presenting their work in forums such as mock trials, town hall-style presentations, gallery walks and formal Power Point presentations. Several classes of students presented their science inquiry research before authentic audiences such as parents, other classes, scientists and school administrators this year. Other classes presented their Project NANO unit final assignments before their peers in their own classes.

\section{PROJECT NANO MODEL FOR TEACHING INQUIRY-BASED NANSCALE SCIENCE WITH CUTTING EDGE TEACHNOLOGY}

The program model developed for Project NANO provides a proven instructional teaching and support platform, a logistical model for using a limited number of resources to reach the maximum number of students and classrooms, and an assessment program that documents how the program is impacting student learning and teacher learning gains. The students who participate in Project NANO, their teachers, and the program staff have all experienced measureable gains in response to the program. The research methodologies are proving to be highly successful in terms of informing adaptive supports that can be provided to individual teachers in the program. Indeed, without exception, teachers and students report a high degree of satisfaction with the program and the supports provided to them.

The looks of pure wonder and fascination as students explore the nature of matter is inspirational to anyone who witnesses the first time children have the opportunity to explore the nanoworld. Indeed, dozens of students in the program said this year that the nanoscale unit was their favorite science unit ever and, of these students, several have 
indicated an interest in exploring nanoscale science college degree and career options in response to this experience. Given that it's not often that one unit can inspire so much curiosity and motivation for students, we include this anecdotal evidence, which when combined with our quantitative evaluation, provide us with multiple lines of evidence and signs of success.

Teachers involved in Project NANO solved a variety of pedagogical and technical challenges related to working with and integrating data with the electron and optical microscopes and using the nanoscale concept with diverse groups of students. Teachers in the program report that the pedagogical and technical strategies they learned through Project NANO are influencing important improvements to their overall teaching practices that have been demonstrated to improve student learning. Thus, the program is doing much more than supporting teachers and students to learn the nanoscale concept and how to use an SEM but is deeply influencing improvement to teaching and learning beyond the nanoscale units of instruction.

The progress made in developing Project NANO places the program in a strong position to grow and replicate the approach in other regions of the U.S. The technical and pedagogical solutions addressed both in terms of the professional development support and in terms of sample units of instruction paired with the rationale for the strategies involved in those units have been carefully and strategically documented to ensure that Project NANO is prepared to disseminate what has been learned. Thus, the program is well positioned to support the implementation of the Next Generation Science Standards and prepare thousands of students to be college and career ready, in addition to the approximately 7500 students served thus far who are already standing on the leading edge of science.

\section{ACKNOWLEDGEMENTS}

Project NANO has operated for this last 3 years with generous support from the M.J. Murdock Charitable Trust, PhenomWorld USA, Nanoscience, Inc., and the College of Letters and Sciences and the Center for Science Education at Portland State University. We thank the Portland State University Foundation and Drake Mitchell and K.C. Hall at Portland State University for their advising and administrative contributions to the program. SLK has been able to continue to lead Project NANO after her retirement from the Department of Geology at Portland State University with permission from the Environmental and Molecular Sciences Laboratory (EMSL), a United States Department of Energy Office of Science User Facility sponsored by the Office of Biological and Environmental Research and located at the Pacific Northwest National Laboratory.

\section{REFERENCES}

[1] National Staff Development Council Learning Forward Program - Standards for Professional Learning. Retrieved from: http://www.learningforward.org/standards-for-professional-learning (2012).

[2] Bransford, J. Thoughts on adaptive expertise (Unpublished manuscript). Available at http://www. vanth. org/docs/AdaptiveExpertise. pdf(2001).

[3] Loughran, J., Milroy, P., Berry, A., Gunstone, R., \& Mulhall, P. (2001). Documenting science teachers' pedagogical content knowledge through PaP-eRs. Research in Science Education, 31, 289-307 (2001).

[4] Bryk, A.S. \& Gomez, L. The research and practice of shaping schools toward evidence-based cultures. A symposium presented at the AERA annual meeting. (papers available at www.iisrd.org) (2007).

[5] Shulman, L.S. "Knowledge and teaching: Foundations of the new reform." Harvard Educational Review, 57, 1-22 (1987). 